\title{
ENTRE A PRÉ-ESCOLA OBRIGATÓRIA E CRECHE OPCIONAL: REFLEXÕES SOBRE O DIREITO DA CRIANÇA À EDUCAÇÃO DE QUALIDADE
}

Jaqueline Delgado Paschoal ${ }^{1}$

\begin{abstract}
Resumo
A interpretação equivocada da Emenda Constitucional $n^{\circ}$ 59/2009, que determinou a matricula obrigatória da criança a partir dos quatro anos de idade, pode levar a pré-escola a ser compreendida como antecipação da escola, e a creche, como espaço de práticas assistencialistas por meio de programas de baixo custo, visto que esta não foi contemplada na prescrição legal. O propósito deste estudo de caráter bibliográfico é discutir o direito da criança à educação de qualidade, independentemente da obrigatoriedade ou da opção da família pelo acesso à creche. Desse modo, muitos são os desafios para que a Educação Infantil cumpra sua finalidade principal, que é a promoção do desenvolvimento integral da criança e a superação da fragmentação do trabalho pedagógico com crianças de zero a cinco anos de idade.
\end{abstract}

Palavras-chave: Creche. Pré-escola. Direitos. Obrigatoriedade. Qualidade.

\section{BETWEEN THE MANDATORY PRE-SCHOOL AND OPTIONAL CRECHE: REFLECTIONS ON THE RIGHT OF THE CHILD TO QUALITY EDUCATION}

\begin{abstract}
The misinterpretation of Constitutional Amendment $n^{\circ}$. 59/2009, which mandated the compulsory enrollment of children from the age of four, can lead to preschool being understood as anticipation of the school, and day care, as a space for welfare practices by low-cost programs, since this was not included in the legal prescription. The purpose of this bibliographic study is to discuss the right of the child to quality education, regardless of the obligation or the option of the family for access to the day care center. Thus, there are many challenges for Early Childhood Education to fulfill its main purpose, which is to promote the integral development of the child and to overcome the fragmentation of pedagogical work with children from zero to five years of age.
\end{abstract}

Keywords: Nursery. Pre-school. Rights. Obligatoriness. Quality.

ENTRE LA PRE-ESCUELA OBLIGATORIA Y CRECER OPCIONAL: REFLEXIONES SOBRE EL DERECHO DEL NIÑO A LA EDUCACIÓN DE CALIDAD 


\section{Resumen}

La interpretación equivocada de la Enmienda Constitucional no 59/2009, que determinó la matrícula obligatoria del niño a partir de los cuatro años de edad, puede llevar a la preescuela a ser comprendida como anticipación de la escuela, y la guardería, como espacio de prácticas asistencialistas por medio de programas de bajo costo, ya que ésta no fue contemplada en la prescripción legal. El propósito de este estudio de carácter bibliográfico es discutir el derecho del niño a la educación de calidad, independientemente de la obligatoriedad o de la opción de la familia por el acceso a la guardería. De este modo, muchos son los desafíos para que la Educación Infantil cumpla su finalidad principal, que es la promoción del desarrollo integral del niño y la superación de la fragmentación del trabajo pedagógico con niños de cero a cinco años de edad.

Palabras clave: Guardería. Preescolar. Derechos. Obligatorio. Calidad.

\section{INTRODUÇÃO}

Quando se parte da história das primeiras instituições de atendimento à criança, nos meados do século XIX, cujo objetivo se resumia aos cuidados e à proteção das crianças enquanto as mães saíam para o trabalho, e se chega até a aprovação da Constituição Federal (1988), que determina o dever do Estado em ofertar creches e pré-escolas para todas as crianças de zero a cinco anos de idade, verificamos um avanço significativo em prol dos direitos da criança à educação desde o nascimento, ensinam e acolhem todas as crianças, independentemente da classe social de origem. Graças à carta constituinte, promulgada há quase três décadas, tanto a creche quanto a pré-escola deixam de constituir espaços de guarda, assistência e compensação, para se consolidarem como instituições eminentemente pedagógicas, que educam, cuidam

A fim de legitimar tal preceito, a Lei de Diretrizes e Bases da Educação Nacional (1996) insere a Educação Infantil como primeira etapa da Educação Básica e aponta sua finalidade principal, que é a promoção do desenvolvimento integral da criança, em seus aspectos: físico, psicológico, intelectual e social. (BRASIL, 1996). Dessa maneira, a função pedagógica se torna indispensável na ação dos professores, considerando-se que cuidados e educação constituem elos mais que significativos e, portanto, inseparáveis, já que “[...] é impossível cuidar de crianças sem educá-las, pois a dicotomia entre essas dimensões se faz somente quando a superficialidade se torna parte da ação de quem lida com as crianças." (PASQUALINI; MARTINS, 2008, p. 78).

No sentido de garantir que todas as crianças usufruam desses espaços, a Política Nacional de Educação Infantil (2006) determina a organização e funcionamento dessas instituições e, principalmente, a expansão da oferta de vagas nas escolas infantis. Ao destacar a indissociabilidade entre as ações de cuidados e educação, essa política ressalta o trabalho coletivo e a articulação entre instituição e família como condição necessária para a 
Artigo

doi: $10.20396 /$ rho.v18i3.8651509

construção de um trabalho que possibilite "[...] o atendimento integral à criança, considerando seus aspectos físico, afetivo, cognitivo, sociocultural, bem como as dimensões lúdica, artística e imaginária.” (BRASIL, 2006, p. 20).

Nosso entendimento é que a criança, principalmente a pequena, depende dos adultos para sua sobrevivência, ou seja, precisa deles para ser educada, cuidada, respeitada e reconhecida em suas especificidades e necessidades, pois a internalização dos objetos da cultura acontece por meio da mediação de pessoas mais experientes. Esse processo, que denominamos desenvolvimento, acontece por meio de educação. (LEONTIEV, 1988).

A cada momento da vida do ser humano, segundo Leontiev (1988), há uma atividade que melhor permite o desenvolvimento da inteligência e da personalidade. $O$ contato da criança com o outro possibilita-lhe o acesso à cultura, que está ligada, diretamente, ao seu convívio social, pois, por meio deste, ela forma para si capacidades, habilidades e aptidões humanas que não são naturais aos seres humanos, mas criadas pelas gerações passadas no decorrer da história e aprendidas pelas novas gerações. (LEONTIEV, 1988).

Desse modo, os espaços de Educação Infantil “[...] podem e devem ser o melhor lugar para a educação das crianças pequenas; pois aí se pode intencionalmente organizar as condições adequadas de vida e educação para garantir a máxima apropriação das qualidades humanas." (MELLO, 2007, p. 89). Nesses espaços, as crianças se apropriam da cultura mais elaborada, por meio do ensino e de atividades intencionalmente pedagógicas.

Corroboramos o pensamento de Mello (2007) que refuta modelos de organização do ensino fundamental transpostos para as escolas infantis, já que a realidade aponta um descompasso entre o que é determinado na legislação e o que é efetivado no cotidiano das escolas infantis. Embora, no campo legal, tenha havido significativos avanços no sentido de reafirmar a importância dessas instituições como espaços de promoção de aprendizagem e desenvolvimento das crianças, a baixa qualidade dos serviços prestados e a falta de clareza sobre as especificidades do trabalho pedagógico com crianças de zero a cinco anos de idade ainda se fazem presentes nas concepções e práticas dos professores.

As condições precárias de funcionamento, a falta de materiais pedagógicos, a ausência de projetos pedagógicos, a baixa escolaridade dos professores e a dificuldade na comunicação com as famílias contribuíram para a precarização do atendimento oferecido às crianças. (CAMPOS; FULLGRAF; WIGGERS, 2006). Além disso, a Emenda Constitucional/EC no 59/2009, aprovada em 2009 (BRASIL, 2009a), ao determinar o ensino obrigatório dos quatro os dezessete anos, a partir de 2016, excluiu a faixa etária de zero a três anos de idade. Embora seja uma estratégia para assegurar o direito à educação de maneira ampliada para todas as crianças a partir dos quatro anos, principalmente, as das camadas mais pobres da população, fragmenta a educação infantil, já que "[...] abala a 
concepção de creche como espaço legítimo de educação e cuidado da criança pequena." (NASCIMENTO, 2011, p. 154).

Concordamos com Nascimento (2011), pois esta autora assinala que a interpretação equivocada da $\mathrm{EC} \mathrm{n}^{\circ}$ 59/2009 pode levar a pré-escola a ser compreendida como antecipação da escola, como ocorreu nos anos de 1970 e 1980, por ocasião da formalização da educação pré-escolar no Brasil, e a creche, como espaço alternativo e, consequentemente, com recurso financeiro insuficiente e mão de obra sem formação adequada. Por outro lado, a falta de qualidade nesses serviços, historicamente, possibilitou a revisão de seu significado e o reconhecimento do "[...] respeito aos direitos da criança, em primeiro lugar, para que fosse possível mostrar a legisladores e administradores a importância da garantia de um patamar mínimo de qualidade para creches e pré-escolas." (CAMPOS; FÜLLGRAF; WIGGERS, 2006, p. 90). Nesse sentido, o objetivo desta pesquisa de caráter bibliográfico é discutir o direito de todas as crianças de zero a cinco anos de idade à educação de qualidade, para além da obrigatoriedade da pré-escola e da opção da família em colocar os filhos menores de três anos em creche. O intuito é sinalizar para os inúmeros desafios dessa etapa da Educação Básica no cenário atual.

\section{A EDUCAÇÃO INFANTIL PÚBLICA, GRATUITA E DE QUALIDADE COMO DIREITO DA CRIANÇA}

O direito à educação desde o nascimento não é conquista atual, pois, há quase trinta anos, a Constituição Federal (1988) determinou, no texto da lei, que esse direito fosse efetivado por meio da oferta de creches e pré-escolas para todas as crianças. No artigo 205, essa lei afirma que a educação é um direito de todos e dever do Estado, e será promovida e incentivada com a colaboração da sociedade. $\mathrm{O}$ artigo 206 estabelece a "[...] igualdade de condições para o acesso e permanência na escola; a gratuidade do ensino público em estabelecimentos oficiais e a garantia de padrão de qualidade." (BRASIL, 1988, p. 123). Além disso, reconhece a educação como um direito público subjetivo e como primeiro direito social do cidadão, pois, conforme o artigo $6^{\circ}$ : "[...] são direitos sociais a educação, a saúde, a alimentação, o trabalho, a moradia, o lazer, a segurança, a previdência social, a proteção à maternidade e à infância, a assistência aos desamparados, na forma desta Constituição.” (BRASIL, 1988, p. 18).

Desse modo, a carta constituinte atribui, no artigo 227, o dever da família e do Estado de assegurar "[...] à criança e ao adolescente, com absoluta prioridade o direito à vida, à alimentação, à educação, além de colocá-los a salvo de toda forma de negligência, discriminação, exploração, violência, crueldade e opressão.” (BRASIL, 1988, p. 132).

Saviani (2013, p. 216) argumenta que "[...] o não atendimento deste direito importa na responsabilização da autoridade competente, então a área jurídica, de modo geral, e o 
Ministério Público, em particular." São essas instâncias que devem garantir a efetivação do direito à educação para todos os cidadãos, desde a mais tenra idade, no Brasil. Segundo o autor, a Constituição avança na garantia dos direitos humanos, pois "[...] se os anos de 1980 foram classificados, do ponto de vista econômico, como a década perdida, no campo da educação estes anos se configuraram como uma década de importantes ganhos." (SAVIANI, 2013, p. 216). A gratuidade, por exemplo, que antes se limitava ao ensino fundamental, a partir dessa lei, estende-se a todo o ensino público, com início na Educação Infantil.

Embora os direitos apareçam no texto da lei, também é importante observar o que, de fato, se concretiza em termos de proclamação desses direitos, pois "[...] a cada direito corresponde um dever, se a educação é proclamada como um direito e reconhecida como tal pelo Poder Público, cabe a este poder a responsabilidade de prover os meios para que o referido direito se efetive." (SAVIANI, 2013, p. 220). Na realidade, o discurso do poder público em defesa da educação "[...] convive, contraditoriamente, com uma visão que enfraquece o papel do Estado em benefício dos mecanismos de mercado negando, na prática, o enunciado constitucional da educação como direito de todos e dever do Estado." (SAVIANI, 2013, p. 221).

Ainda assim, vale destacar que educação da criança em espaços coletivos, que esteve à margem do sistema educacional brasileiro desde a sua origem, passa a ser direito de todas as crianças a partir da promulgação da Constituição, visto que essas são consideradas sujeito de direitos, inclusive o da educação desde o nascimento. Daí o avanço significativo dessa lei, que assevera, no artigo 208, que o dever do Estado em relação à educação será efetivado mediante a garantia de:

I - educação básica obrigatória e gratuita dos 4 (quatro) aos 17 (dezessete) anos de idade, assegurada inclusive sua oferta gratuita para todos os que a ela não tiveram acesso na idade própria.

IV - Educação Infantil, em creche e pré-escola, às crianças até 5 (cinco) anos de idade. (BRASIL, 1988, p. 124).

A educação como direito da criança também está prevista no Estatuto da Criança e do Adolescente/ECA (1990), que determina o dever do Estado e da família na preservação dos direitos fundamentais da pessoa humana, por meio do acesso a oportunidades que favoreçam o desenvolvimento físico, mental, moral, espiritual e social, em condições de liberdade e dignidade, tanto da criança, quanto do adolescente. (BRASIL, 1990).

Bazílio (2003) considera a promulgação do ECA (BRASIL, 1990) decisiva para a consolidação dos direitos da criança no Brasil, por dois motivos: primeiro, em função da "[...] ampla participação de setores da sociedade civil na mobilização e redação da nova lei, já que trata-se de anos gloriosos, ao contrário dos códigos de menores elaborados por experts" (BAZILIO, 2003, p. 20) nos anos de 1927 e 1979; segundo, “[...] porque do 
ponto de vista conceitual o Estatuto abandona o paradigma da infância em situação irregular e adota o princípio de proteção integral à infância.” (BAZÍLIO, 2003, p. 21).

É importante ressaltar que o Estatuto parte "[...] da concepção da criança como sujeito de direitos em contraposição aos textos anteriores prescritos nos Códigos de Menores de 1927 e 1979, que as viam como objeto." (BAZÍLIO, 2003, p. 24). O objetivo é "[...] a desjudicialização das questões relativas à infância em contraposição ao papel e a interferência do Poder Judiciário que, com o Código de Menor de 1979, teve aumentado sua intervenção e poder." (BAZÍLIO, 2003, p. 24). Por outro lado, esse autor esclarece que, embora essa lei tenha avançado, significativamente, no estabelecimento dos direitos, "[...] esta política setorial apresenta problemas muito graves na sua operacionalização." (BAZÍlIO, 2003, p. 26).

Para Bazílio (2003, p. 26):

Fatos como a superlotação de internatos com sucessivas rebeliões-em que jovens morrem sob a tutela do Estado, baixa qualidade e desempenho dos programas de liberdade assistida, ausência de financiamento para sustentar ações, ocupam grandes espaços na imprensa. De fato, apesar de algumas iniciativas exitosas estamos diante de grave crise.

Bazílio (2003), entende que não basta reconhecer a criança e o adolescente como cidadãos de direitos, mas é preciso que o Estado assuma sua responsabilidade social no sentido de oferecer políticas públicas que promovam uma educação de qualidade em qualquer nível ou modalidade de ensino.

Corrêa (2003), ao discutir o conceito de qualidade, destaca dois artigos do ECA que reafirmam o dever da sociedade em garantir os direitos dos menores de dezoito anos, sendo que um deles é o artigo $5^{\circ}$, que estabelece: “[...] nenhuma criança ou adolescente será objeto de qualquer forma de negligência, discriminação, exploração, violência, crueldade e opressão, punido na forma da lei qualquer atentado, por ação ou omissão, aos seus direitos fundamentais." (BRASIL, 1990, p. 12). Ao tratar do direito à educação no artigo $53^{\circ}$, o ECA define que este deve assegurar, entre outros aspectos: "[...] o direito de ser respeitado por seus educadores." (CORRÊA, 2003, p. 91).

No que diz respeito ao trato com as crianças pequenas, a autora explica que, de modo especial, devido às "[...] limitações de autodefesa das crianças em razão de sua pouca idade, isto é absolutamente relevante, visto que em algumas instituições, práticas como os castigos de toda natureza, algumas vezes físicos, ainda se fazem presentes." (CORRÊA, 2003, p. 91). Entretanto, segundo a autora:

O fato de haver uma lei contra isso não garante, evidentemente, a sua superação, mas representa, sem dúvida, um poderoso instrumento de repressão a essas práticas. Ademais, de uma outra forma, o conteúdo desses artigos reafirma a Constituição, indicando ser possível acionar o Estado para que ele não apenas cumpra seu dever de oferecer o atendimento a todos que assim o queiram mas, 
além disso, que o faça baseado no respeito aos direitos das crianças, ou seja, com qualidade. (CORRÊA, 2003, p. 91).

Nesse sentido, a Lei de Diretrizes e Bases da Educação Nacional (1996), ao tratar da composição dos níveis escolares, destaca, no artigo $29^{\circ}$, que o objetivo principal da Educação Infantil é a promoção do desenvolvimento integral da criança. No artigo $30^{\circ}$, que foi alterado pela Lei $\mathrm{n}^{\circ} 11.114 / 2005$, determina que essa etapa "[...] será oferecida em creches ou equivalentes, para crianças de até três anos de idade; pré-escolas para crianças de quatro a cinco anos de idade." (BRASIL, 1996, p. 17). Outro avanço que a lei traz refere-se à avaliação, que não tem a finalidade de promoção ou retenção da criança, pois, em seu artigo $31^{\circ}$, estabelece que "[...] a avaliação far-se-á mediante acompanhamento e registro do seu desenvolvimento, sem o objetivo de promoção, mesmo para o acesso ao ensino fundamental." (BRASIL, 1996, p. 17).

O tratamento dos vários aspectos como dimensões do desenvolvimento e não como áreas separadas foi fundamental, pois isso "[...] evidencia a necessidade de se considerar a criança como um todo, para promover seu desenvolvimento integral e sua inserção na esfera pública." (BRASIL, 2006, p. 10). Desse modo, verifica-se um avanço importante no que tange aos direitos da criança à educação de qualidade.

Pesquisas realizadas por Campos (2013, p. 24) sobre a qualidade dos sistemas de ensino na América Latina, no entanto, indicam que o discurso da qualidade encobre a luta pelo acesso à educação, visto que "[...] as organizações escolares contribuíram para a reprodução da estrutura social, muito mais por meio de processos de exclusão do que por mecanismos internos de reforço da desigualdade." Essa exclusão se acentua nos grupos marginalizados da população, principalmente nas regiões rurais e nas periferias pobres das grandes cidades.

Embora, nas últimas décadas, tenha havido uma significativa expansão de matrículas em quase todos os países, principalmente nos ensinos primário e secundário, mas também na pré-escola, Campos (2013, p. 3), em seus estudos, observou um deslocamento da preocupação do poder público, que tem, aos poucos, migrado da democratização do acesso para uma ênfase na qualidade da educação, “[...] que acompanha a crescente presença de crianças, adolescentes e jovens das camadas mais pobres nas escolas públicas."

A desigualdade se faz presente, segundo Campos (2013, p. 4), justamente pela educação não ser a mesma para todos e por, nem sempre, atender as necessidades dos diferentes grupos sociais, assim, "[...] a expansão horizontal e vertical dos sistemas escolares reflete as características de desigualdade da sociedade.” Além disso, na prática, os "[...] sistemas nacionais e internacionais de avaliação aplicados pelos sistemas de ensino procuravam mensurar os resultados de aprendizagem dos alunos das escolas de ensino 
regular e médio, por meio de indicativos de comparações entre escolas, cidades, regiões e países." (CAMPOS, 2013, p. 28).

Nessa perspectiva, Corrêa (2003, p. 26) enfatiza que "[...] a qualidade da educação passou a ser definida principalmente por esses indicadores, os quais reiteraram, com base em critérios que ganharam grande legitimidade pública, as diferenças sociais entre os alunos", o que acentua ainda mais as desigualdades nas formas de atendimento dos diferentes níveis de ensino. Os estudantes de escolas privadas, por exemplo, "[...] obtêm geralmente melhores resultados do que os matriculados em escolas públicas, com exceção das universidades, onde o sinal se inverte." (CORRÊA, 2003, p. 27). As regiões mais desenvolvidas, segundo Corrêa (2003, p. 27), "[...] alcança melhores resultados do que alunos de regiões mais pobres, especialmente zonas rurais; os grupos étnico-raciais discriminados têm piores resultados do que os demais."

Além disso, segundo Campos (2013), nas regiões mais desenvolvidas, as taxas de matrícula em creche são mais elevadas do que nas demais, assim como nas áreas urbanas, quando comparadas às áreas rurais. É importante mencionar que "[...] as crianças de famílias com renda per capita mais baixa apresentam taxas de matrícula significativamente mais baixas, assim como as crianças não brancas." (CAMPOS, 2013, p. 31). Outro dado importante diz respeito ao atendimento "[...] de crianças muito pequenas em creches, por longas horas diárias, sem a garantia de condições mínimas de qualidade, o que pode prejudicá-las em seu desenvolvimento e desrespeitá-las em seus direitos." (CAMPOS, 2013, p. 36).

A fim de reverter esse quadro e com o objetivo de contribuir para a implementação de práticas educativas de qualidade em escolas infantis, o Ministério da Educação publicou o documento Parâmetros Nacionais de Qualidade para a Educação Infantil (BRASIL, 2009b), volumes 1 e 2, com o objetivo de estabelecer parâmetros de qualidade locais, com base nos padrões de referência nacional para os sistemas de ensino, sobretudo no que se refere à organização e funcionamento das escolas infantis.

O primeiro volume discute aspectos relevantes, como: concepção de criança e de educação infantil; legislação; e trajetória histórica do debate sobre a qualidade do trabalho nas instituições de atendimento à criança. O segundo volume aborda as competências dos sistemas de ensino, a caracterização das escolas infantis a partir de definições legais e, na sequência, apresenta: os parâmetros de qualidade; a autonomia das instituições para a elaboração de propostas pedagógicas; a formação adequada de professores e gestores; espaços, materiais e equipamentos adequados para o pleno funcionamento das escolas infantis, entre outros aspectos para a implementação de parâmetros de qualidade locais. (BRASIL, 2009b).

Na realidade, ao definir esses padrões, a preocupação não foi apontar um padrão mínimo nem máximo, mas estabelecer “[...] os requisitos necessários para uma educação 
infantil que possibilite o desenvolvimento integral da criança até cinco anos de idade, em seus aspectos físico, psicológico, intelectual e social.” (BRASIL, 2009b, p. 09).

Segundo Massucato e Azevedo (2012), para que a qualidade dos serviços prestados contribua, efetivamente, para a aprendizagem e o desenvolvimento das crianças, é necessário que os professores se reconheçam como profissionais, pois não basta gostar de crianças, já que o conhecimento sobre as especificidades desse nível de ensino é que faz a diferença em relação aos que atuam sem formação adequada. As autoras argumentam que, apesar das proposições legais em defesa da educação da criança nas últimas décadas, ainda existem lacunas "[...] no sentido de estabelecer e preservar a qualidade da educação enquanto um direito das crianças, havendo diferentes concepções sobre a criança, a Educação Infantil e os seus profissionais.” (MASSUCATO; AZEVEDO, 2012, p. 152).

Desse modo, reconhecer as peculiaridades das crianças é indispensável para um trabalho pedagógico de qualidade, sobretudo no que tange à compreensão de que as crianças são indivíduos em formação e que, segundo os documentos legais, "[...] já são cidadãs e possuem direitos, inclusive de ter um lugar planejado para sua aprendizagem e desenvolvimento." (MASSUCATO; AZEVEDO, 2012, p. 153). Nesse contexto, há a necessidade de um profissional que possa intervir, de forma intencional, no desenvolvimento da criança, de modo a lhe garantir o acesso e a apropriação do conhecimento historicamente produzido. O desafio que se coloca é a garantia não só de padrões de qualidade dos serviços prestados, mas o reconhecimento social de que a Educação Infantil é relevante e necessária como espaço legítimo de educação das crianças.

Dessa forma, a EC nº 59/2009 (BRASIL, 2009a), que tornou o ensino obrigatório a partir dos quatro anos de idade, pode representar um retrocesso histórico e "[...] levar novamente à cisão na Educação Infantil, entre a creche e a pré-escola, e também à escolarização precoce das crianças de quatro a cinco anos de idade" (NASCIMENTO, 2011, p. 155), pois, para legitimar tal determinação, foi sancionada a Lei ${ }^{\circ}$ 12.796/2013, que altera o Art. $6^{\circ}$ da LDB (1996) e determina que é "[...] dever dos pais ou responsáveis efetuar a matrícula das crianças na educação básica a partir dos quatro anos de idade." (BRASIL, 2013, p. 02).

Nessa perspectiva, Pinazza e Santos (2016, p. 23) ressaltam que é preciso desenvolver reflexões "[...] sobre os perigos que se avizinham diante dessa medida legal dada pela Emenda n ${ }^{\circ} 59$ ", já que o poder público, por meio de prescrições legais, ora reconhece a criança como sujeito de direitos, inclusive o direito à educação, ora determina o dever de ingressarem compulsoriamente no sistema de ensino a partir de quatro anos de idade. (PINAZZA; SANTOS, 2016).

A preocupação é que, tendo como base os argumentos de universalização de acesso e a garantia de maior tempo de permanência na escola, a pré-escola "[...] continue a ser chamada a responder indevidamente pela preparação para os anos seguintes da 
escolarização, localizando, na pré-escola, o foco de transformação de uma escola de ensino fundamental que deve ser pensada a partir dela própria." (PINAZZA; SANTOS, 2016, p. 24).

No plano pedagógico, a excessiva escolarização da criança, evidenciada pela organização tradicional dos espaços, por atividades e equipamentos pouco adequados à faixa etária, incluindo, o uso de carteiras próprias para crianças maiores, enfileiradas como no ensino regular, além de não respeitar as especificidades da criança, fragmenta a Educação Infantil, que passa a se assemelhar ao ensino fundamental, sobretudo no que tange à organização do tempo, do espaço e da proposta pedagógica.

Para Silva (2011, p. 374), além da fragmentação desencadeada entre creche e préescola, "[...] o maior desafio para a expansão da oferta da Educação Básica situa-se na creche, que, para atender à população na faixa etária até três anos, deveria ter uma ampliação de cerca de 56,5\%." O fato de a creche não ter sido contemplada, como prioridade, na utilização de recursos públicos pela EC nº 59/2009 (BRASIL, 2009a), segundo a autora, pode levar à exclusão de crianças de até três anos de idade do sistema educacional. Além disso, a autora esclarece que a garantia dos direitos de todas as crianças a um atendimento que respeite suas especificidades passa "[...] pela existência de profissionais qualificados para atuar nessa fase, pois é preciso que se tenha clareza das especificidades das crianças pequenas e das instituições de educação infantil." (SILVA, 2011, p. 376). Assim, há necessidade de se valorizar esses profissionais frente aos demais da Educação Básica, segundo Silva (2011).

O desafio que a obrigatoriedade traz em relação à formação dos profissionais que atuam ou que atuarão na pré-escola também é preocupante, pois, diante da determinação legal de oferta de vagas, há, concomitantemente, a necessidade de mais profissionais qualificados para essa área. (PINAZZA; SANTOS, 2016). Sobre essa questão, Saviani (2009) afirma que, embora as políticas formativas tenham sofrido contínuas mudanças, devido à sua precariedade não conseguiram "[...] estabelecer um padrão minimamente consistente de preparação docente para fazer face aos problemas enfrentados pela educação escolar em nosso país." (SAVIANI, 2009, p. 148).

Saviani (2009) identifica a existência de dois modelos de formação: o primeiro tem como foco conteúdos culturais-cognitivos, que priorizam a cultura geral e o domínio específico de conteúdos da área de conhecimento em que o professor irá lecionar; e o segundo aborda conteúdos pedagógico-didáticos que valorizam o efetivo preparo pedagógico-didático do profissional. Para o autor, o problema pode estar situado na dicotomia entre dois aspectos indissociáveis da função docente: forma e conteúdo, ou seja, o que ensinar e como ensinar. Nesse sentido, para Saviani (2009), dois aspectos devem ser observados: por um lado, espera-se que a base de cultura geral clássica e científica, obtida nos cursos de nível médio, auxilie os futuros professores, nos cursos formativos de nível 
Artigo

doi: $10.20396 /$ rho.v18i3.8651509

superior, a adquirirem um preparo profissional bem mais consistente, alicerçado em uma sólida cultura pedagógica.

Por outro lado, entretanto, há o risco de que essa formação seja neutralizada pela força do modelo baseado em conteúdos culturais- cognitivos, o que tenderia a secundarizar as exigências pedagógicas. Nesse contexto, os novos professores teriam "[...] grande dificuldade de atender às necessidades específicas das crianças pequenas, tanto no nível da chamada Educação Infantil como das primeiras séries do ensino fundamental." (SAVIANI, 2009, p. 150).

Além disso, apesar de a LDB (1996) ter excluído a participação de professores leigos do sistema de ensino, já que determinou a formação em nível superior, em cursos de licenciatura, de graduação plena, em universidades e institutos superiores de educação, admitiu "[...] como formação mínima para o exercício do magistério na educação infantil, e nos cinco primeiros anos do ensino fundamental, a formação oferecida em nível médio, na modalidade normal." (BRASIL, 1996, p. 26).

O desafio consiste em unificar as "[...] políticas de formação inicial com as de valorização docente, pois as condições precárias de trabalho neutralizam a ação dos professores, mesmo que estes sejam bem formados." (SAVIANI, 2009, p. 153). As situações empobrecedoras de trabalho, segundo o autor, também desestimulam os jovens a optar pela docência. Daí a importância de políticas públicas que reconheçam que a formação inicial e continuada dos professores é condição essencial para um atendimento que respeite os direitos fundamentais das crianças.

Desse modo, a organização de um ambiente acolhedor se faz necessária, considerando-se que a Educação Infantil constitui um espaço que "[...] proporciona à criança viver experiências, explorar e resolver problemas, construir significados sobre o mundo, interagir com o outro, estabelecer relações, criar, imaginar e principalmente brincar." (OSTETTO, 2009, p. 11). Assegurar um ambiente pautado nas necessidades da criança e em seu direito à educação é papel fundamental nesse nível de ensino, além de ser uma forma de "[...] caminhar no sentido da quebra de estereótipos e generalizações, rompendo com o modelo ideal, de uma criança sem rosto, abstrata.” (OSTETTO, 2009, p. 11). Assim, é indispensável aprender a ver e ouvir as crianças concretas e mostrar-lhes que a escola pode ser um espaço para a expressão de suas diferentes linguagens. A garantia do desenvolvimento profissional e a formação continuada, portanto, são condições primordiais para assegurar o direito da criança à educação de qualidade desde a mais tenra idade. 


\section{CONSIDERAÇÕES FINAIS}

Diante da obrigatoriedade da pré-escola e da opção das famílias pelo ingresso das crianças em creches, podemos afirmar que muitos são os desafios da Educação Infantil na atualidade. Apesar de haver unanimidade, no poder público, na sociedade civil e entre pesquisadores da área, sobre o direito da criança à educação desde o nascimento, o desafio é consolidar, efetivamente, não só os direitos no âmbito educativo, mas garantir todos os outros previstos nas leis para todas as crianças brasileiras. Assim, repensar o atendimento oferecido às populações infantis, em espaços coletivos, requer um compromisso permanente das diferentes instâncias, no sentido de oferecer políticas públicas que garantam, na prática, a efetivação do direito à vida, à moradia, à educação de qualidade, entre tantos outros.

O reconhecimento da Educação Infantil como espaço pedagógico e complementar à educação familiar também se torna um desafio, pois a família deve assumir a educação dos filhos e compartilhar essa educação em espaços que enriqueçam e ampliem as experiências infantis.

A efetivação de um trabalho pedagógico que contribua para a ampliação do universo das crianças, em termos de aprendizagem e desenvolvimento, se faz necessária, pois a existência de contradições entre o que é determinado pelas leis e o que é, realmente, efetivado no contexto da Educação Infantil, é fato bastante presente no Brasil. Nesse sentido, a interpretação equivocada da Emenda Constitucional $\mathrm{n}^{\circ}$ 59, de 2009, pode contribuir para práticas de escolarização precoce, sobretudo no que diz respeito à alfabetização, e, por outro lado, para o retorno de ações assistencialistas em creches, com profissionais sem formação adequada.

Dessa forma, à luz dos elementos analisados, consideramos que a formação inicial de professores e a valorização docente, em termos de carreira e salários, são condições primordiais para a consolidação dessa etapa da Educação Básica. Para além dessas questões, acreditamos que a Educação Infantil deve ser reconhecida e valorizada como espaço capaz de humanizar as crianças, por meio de práticas coletivas, de trocas de experiências e da apropriação de diferentes saberes.

\section{REFERÊNCIAS}

BAZÍLIO, L. C. Avaliando a implantação do estatuto da criança e do adolescente. In: BAZÍLIO, L. C.; KRAMER, S. (Org.). Infância, educação e direitos humanos. São Paulo: Cortez, 2003. p. 19-28.

BRASIL. Constituição (1988). Constituição da República Federativa do Brasil. Brasília, DF: Senado Federal, 1988, 305 p. 
Artigo

doi: $10.20396 /$ rho.v18i3.8651509

BRASIL. Decreto-lei no 8.069, de 13 de junho de 1990. Aprova o Estatuto da criança e do adolescente. Brasília: Câmara dos Deputados, Edições Câmara, 1990. 207 p. (Série legislação, n. 83).

BRASIL. Emenda Constitucional $n^{\circ} 59$, de 11 de novembro de 2009. Acrescenta § 3o ao artigo 76 do ato das disposições constitucionais transitórias. Diário Oficial da União, 12 nov. 2009a. Seção 1, p. 8.

BRASIL. Lei n ${ }^{\circ}$ 9394, de 20 de dezembro de 1996. Dispõe sobre as Diretrizes e Bases da Educação Nacional. Brasília, DF: MEC, 1996.

BRASIL. Lei ${ }^{\circ} 12.796$ de 04 de abril de 2013. Altera a Lei ${ }^{\circ} 9.394$ de 20 de dezembro de 1996 da Lei de Diretrizes e Bases da Educação Nacional dispor sobre a formação dos profissionais da educação e da outras providências. Brasília: 2013.

BRASIL. Ministério da Educação e do Desporto. Secretaria de Educação Básica. Parâmetros Nacionais de Qualidade para a Educação Infantil. V. 1 e 2. Brasília, DF: $\mathrm{MEC} / \mathrm{SEB}, 2009 \mathrm{~b}$.

BRASIL. Ministério da Educação e do Desporto. Secretaria de Educação Básica. Política Nacional de Educação Infantil. Brasília, DF: MEC/SEB, 2006.

CAMPOS, M. M. Entre as políticas de qualidade e a qualidade das práticas. Cadernos de Pesquisa, n. 148, p. 22-43, 2013. Disponível em: <www.scielo.br/pdf/cp/v43n148/03. pdf>. Acesso em: $20 \mathrm{dez} .2017$.

CAMPOS, M. M.; FULLGRAF, J.; WIGGERS, V. A qualidade da educação infantil brasileira: alguns resultados de pesquisa. Cadernos de Pesquisa, São Paulo, n. 127, p. $87-$ 128, 2006. Disponível em: <www.scielo.br/scielo.php?pid=S0100-15742006000100005\& script>. Acesso em: $31 \mathrm{dez} .2017$.

CORRÊA. B. C. Considerações sobre qualidade na educação infantil. Cadernos de Pesquisa, n. 119, p. 85-112, 2003. Disponível em: <www.scielo.br/pdf/cp/n119/ n119a05.pdf>. Acesso em: 29 set. 2017.

LEONTIEV, A. Os princípios psicológicos da brincadeira escolar. In: VYGOTSKY, L. S. et al. (Org.). Linguagem, desenvolvimento e aprendizagem. Trad. Maria da Penha Villa Lobos. São Paulo: Ícone; Ed. da EDUSP, 1988. p. 127-144.

MASSUCATO, J. C.; AZEVEDO, H. O. de. Identidade da educação infantil e de seus professores: perspectivas de reconstrução. Revista de Educação PUC-Campinas.

Campinas, n. 17, p. 151-161, 2012. Seção Temática: Educação Infantil: história, políticas e perspectivas. Disponível em: <periodicos.puc-campinas.edu.br/seer/index.php/ reveducacao/article/view/1004>. Acesso em: 03 set. 2017.

MELLO, S. A. Infância e humanização: algumas considerações na perspectiva históricocultural. Perspectiva, Florianópolis, v. 25, n. 1, p. 83-104, jan./jun. 2007. Disponível em: 
<https://periodicos.ufsc.br/index.php/perspectiva/article/viewFile/1630/1371〉. Acesso em: 20 out. 2017.

NASCIMENTO. M. L. Algumas considerações sobre a infância e as políticas de educação infantil. Educação \& Linguagem, v. 14, n. 23, p. 146-159, 2011. Disponível em:

<https://www.metodista.br/revistas/revistas-ims/index.php>. Acesso em: 22 out. 2017.

OSTETTO, L. Na dança e na educação: o círculo como princípio. Educação e Pesquisa v. 35, p. 177-193, 2009.

PASQUALINI, J. C.; MARTINS, L. M. A educação infantil em busca de identidade: análise crítica do binômio "cuidar-educar" e da perspectiva anti-escolar em educação infantil. Psic. da Ed., São Paulo, n. 27, p. 71-100, 2008. Disponível em:

<pepsic.bvsalud.org/scielo.php.script>. Acesso em: 20 jan. 2018.

PINAZZA, M. A.; SANTOS, M. W. A (pré)-escola na lógica da obrigatoriedade: um desconcertante 'dejà vu'?. Textura Canoas, v. 18, n. 36, p. 22-43, 2016. Disponível em: <www.periodicos.ulbra.br/index.php/txra/issue/view/147>. Acesso em: 20 jan. 2018.

SAVIANI. D. A educação na Constituição Federal de 1988: avanços no texto e sua neutralização no contexto dos 25 anos de vigência. RBPAE, v. 29, n. 2, p. 207-221, 2013. Disponível em: <seer.ufrgs.br/index.php/rbpae/article/view/43520>. Acesso em: 05 jan. 2018.

SAVIANI, D. Formação de professores: aspectos históricos e teóricos do problema no contexto brasileiro. Revista Brasileira de Educação, Rio de Janeiro, v. 14, n. 40, p. 143155, jan./abr. 2009. Disponível em: <www.scielo.br/pdf>. Acesso em: 04 ago. 2017.

SILVA, A. da. Escolarização obrigatória e formação de professores para a educação infantil. Revista Retratos da Escola, Brasília, v. 5, n. 9, p. 371-383, 2011. Disponível em: <http//www.esforce.org.br>. Acesso em: 10 jan. 2018.

\section{Notas}

${ }^{1}$ Pós-Doutora em Educação pela Universidade Júlio de Mesquita Filho/UNESP/Assis. Professora Adjunta no Departamento de Educação da Universidade Estadual de Londrina. Docente no Programa de Pós-GraduaçãoMestrado e Doutorado em Educação da UEL.

Submetido em: 09/03/2018

Aprovado em: 30/08/2018

Publicado em: 28/09/2018 